\title{
Sentido Social de la Rebelión de Túpac Amaru
}

\author{
Por Daniel Valcárcel
}

La histórica rebelión de José Gabriel Condorcanqui Noguera y Túpac Amaru -mestizo serrano, caudillo de masas indias- pertenece a la etapa predominante social y fidelista de fines del siglo XVIII Y principios del XIX, precursora todavia no-conciente de una futura etapa predominantemente política y separatista entre los años 1816 a 1826 - coincidente, más o menos, con la llegada de Brown al litoral y la salida de Abascal- a través de un intermediario momento socio-político y liberal que corre desde la iniciación del siglo XIX hasta el año 1815. Porque el separatismo peruano -conciente tendencia política que aspiraba a la formación de un nuevo Estadoa ho se inicia ya como tal separatismo - según algunos quieren sostener sino que en verdad constituye la culminación de un proceso que brota como disconformidad local y cotidiana contra la mala administración colonial, pero que simultáneamente - tanto en su forma progresista como en la ultramontana- acepta el absolutismo de la monarquía imperante -momento fidelista-; se afianza, cuando a la antedicha protesta social se agrega una crítica ideológica de tendencia monárquico-constitucional -momento liberal-; y culmina con la secesión en instantes cronológicos distintos a ctros análogos sucesos contemporáneos de hispanoamérica -momento separatista.

La inicial etapa fidelista está caracterizada por una profunda disconformidad social, que apunta su intermitente ataque contra las malas autoridades -obstáculos a la vigencia de las Leyes de Indias, cabe decir a la auténtica voluntad del Rey (1). De esta etapa toda-

(1) V. mis ensaycs Rebeliones Indigcuas (Lima, Imp. Torres Aguirre, 1946, pp. 13-29) y La rebelioin de Tífac Amarn (México, Edit. Fondo de Cultura Económica, 19+7, caps. I-VI). 
vía ingenua, se pasará a otra, análoga a la representada por la ilus tración española del reinado de Carlos III, que en el Perú florece tardía por la época de Gil de Taboada -en simultáneo momento al de la lucha en España contra la intromisión de la ola revolucionaria francesa en pleno proceso de expansión. En esta etapa social y fidelista - cuyos orígenes pueden ser encontrados en la tensión de nuestros ultramontanos y regalistas- vive y se consume el cacique Túpac Amaru (1740 ó 41-1781). Desde un punto de vista genérico, hasta cuatro generaciones podrían ser divisadas a lo largo del complejo siglo XVIII peruano : a) constituída por hombres nacidos en la primera mitad del siglo XVIII, como Llano Zapata, Olavide, Castro, Pumacahua y Túpac Amaru -cuyas diferencias serán abordadas más adelante-, b) formada por los nacidos a comienzos de la segunda mitad del siglo XVIII, como Rodríguez de Mendoza, Baquíjano y Carrillo, Morales Duárez, Unanue o Araníbar, c) tipificada por los que nacieron a mediados de la segunda mitad de esta centuria, como Vidaurre, Luna Pizarro, Arce, Luzuriaga, Riva Agüero, Gamarra o Sánchez Carrión, y d) constituída par los nacidos a fines del mencionado lapso, como Choquehuanca, González Vigil, Orbegoso o Castilla.

La primera generación tiene dos grupos : I) el formado por los limeños Llano Zapata y Olavide, que pasan a España y se insertan en el proceso europec-americano par̆a no retornar jamás, y II) el constituído por Castro, Pumacahua $y$ Túpac Amaru, cuyas actividades tienen como sede" Ialjurisdicción del obispado "del Cusco y muestra una trayectoria peculiar. Castro es un polígrafo tacneño, cuỵa actitud local se mezcla con otra de carácter ecuménico y juega papel importante en la cultura peruana de la época. Pumacahua y Túpac Amaru son dos Caciques, individuos pertenecientes a la casta noble indígena, que actuarán en bandos diferentes durante los célebres y violentos sucescs del Cusco de 1780. Túpac Amaru desaparecerá en 1781, sin rebasar la etapa fidelista, en tanto que Pumacahua - colmado de máximos honores por el Rey- en sus años de ancianidad encabeza una rebelión, que coincide con nuestro lapso liberal, y - como Túpac Amaru-perecerá también en la empresa.

Ahora bien, cómo ha sido interpretada esta epónima rebelión cusqueña por los escritores en épocas diversas?. Ya durante el siglo XVIII, un sector de tendencia oficial interesada, la señaló como: un movimiento político de secesión. Era una cazurra manera de alarmar a la Corte, evitar mayores averiguaciones y defender los intereses creados de las malas autoridades. Otro sector señaló su carácter de pro- 
testa por la creación de nuevos impuestos. Más tarde, al producirse la independencia y años siguientes, se consideró a este acontecimiento que encabezara Túpac Amaru como un conato separatista, juzgándose el pasado histórico de acuerdo con los sentimientos predominantes en aquel momento. En nuestra actual etapa pueden ser descubiertas dos actitudes : una subjetiva, poco crítica y documentada, que coge opiniones y las acepta sin mayor examen, c enuncia juicios rotundos basados en algunas hojas sueltas, por ejemplo sosteniendo la tesis del separatismo apoyado en un bando, que Melchor Paz señala haber sido encontrado "en la faltriquera del Vestido" de Túpac Amaru; y otra objetiva, que considera a esta rebelión como representativa de un movimiento social preñado de inusitadas consecuencias, apoyada en un análisis de los caracteres imperantes en aquella época, en las actitudes de sus personajes y en lo que escribió el propio Túpac Amaru y su esposa, doña Micaela Bastidas. Un breve derrotero bibliográfico ha sido publicado por el suscrito bajo el título de Estado de la investigación histórica sobre la rebelión de Túpac Amaru (2).

¿Quién era Túpac Amaru y qué fuentes directas ha dejado para el conocimiento histórico de la rebelión que capitaneó? Como Cacique, fué Túpac Amaru un funcionario menor de la Corona española, descendiente de la antigua nobleza incaica. Su Genealogía ha sido publicada, pero hay dcicumentos inéditos, de otro equívoco pretendiente del siglo XVIII a ser reconocido como el verdadero representante del último Inca, en la Universidad (delSan AntonioeldelCuscor(3). Su educación la efectuó en el Colegio de San Francisco de Borja de esa ciudad -destinado a las hijos de Caciques con derecho de sucesión- plantel regentado por los jesuítas, donde se les impartía elementos de cultura y se les adoctrinaba en la religión.

Por sus actividades posteriores, se infiere que el cacique Túpac Amaru siguió cultivándose hasta poseer un cierto conocimiento de las Leyes de las Indias y de ctras normas jurídicas españolas, con ayuda posible de un consultor. Lo prueba el recurso que presentó ante la Audiencia de Lima, el 18 de diciembre de 1777, como representante de los Caciques de la provincia de Tinta para solicitar la extinsión del servicio a la mita de Potosí. Cuando retornó al Cusco desengañado

(2) v. Rev. Mar del Sur, Lima IX-X-1949, no 7, pp. $42-53$.

(3) v. mis folletos Intice de Documentos referentes al juicio sobre legitima descendencia del úllimo Inca Trijne llmaru (Lima, Imp. Miranda, ig+8) y La familia del Cacique Túpac 1 maru (Lima, Imp. Miranda, 1947). 
de la justicia virreinal, al cómenzar el año siguiente, serćs el momento en que adoptará nuevas actitudes. Si la justicia no se podía obtener mediante gestiones pacíficas, necesario era obtenerla por la fuerza. La ley debia acatarse a despecho de las malas autoridades, pero olvidaba que el desacato no sería perdonado por el Rey, aunque fuera ejecutado en su nombre, y los dolosos manejos de Corregidores, Recaudadores y demás funcionarios cómplices estaban a cubierto de toda sanción oficial.

Pcr entonces son ya numerosos los motines contra los nuevos impuestos y los ataques personales que sufren de continuo los Recaudadores de la Real Hacienda. La Memoria de Amat hace referencia a tumultos en diversos pueblos del Perú, situación que sufre un notable incremento en la de su sucesor Guirior, como testimonio decisivo del malestar imperante. Los peruanos -y los americanos- comenzarán por no creer en las malas autoridades, que a despecho de la distancia burlan las leyes, y terminarán por sacudirse del propic. Monarca.

Túpac Amaru parece no haber preparado extensas conexiones previas, sino guardado hasta el último momento su arriesgado designio. Prefirió escrutar el ambiente y esperar una ocasión favorable a la prapagación de su grito de justicia social. Esto significa conocimiento del medio y cautela, porque la delación abundaba. Cuando en 1780 envió cartas a los Caciques de las diferentes Provincias, muchos de ellos fueron las primeros Jen gavisarcailas autoridadeso (4). El bagaje bélico y los conocimientos militares están casi ausentes. No hay un plan de guerra. En la rebelión del Cacique está presente ese característico impulso de los gritos sociales, fundamentado sobre la esperanza de una propaganda rápida y su inmediato eco en las masas.

Túpac Amaru se constituye en el vacero de una casta no-privilegiada, haita de cargas y amarras que desea sacudir de su vida cotidiana. Protesta contra los abusos, pero deja constancia que su movimiento no va contra el Rey ni la religión. En toda hispanoamérica se oirán gritos análogos. Paradójicamente, las autoridades son acusadas Y están en plano vedado. Los verdaderos súbditos americanos de Carlos III son aquellos que, a despecho de los intereses creadas, luchan por el imperio de la ley. En la primera parte de su Diálogo sobre los Sucesos varios acaecidos en este Reyno del Perú, escrito en 1786 par

(4) v. La rebelión de Túpac Amaru, cap. VIII. 
Melchor Paz (5), se insertan, entre otros documentos, tres Cartas dirigidas al Obispo, al Cabildo secular y a un Canónigo de La Paz, trascritas en la parte final del presente trabajo (6). Pedro de Angelis publica las dos primeras, omite la tercera, y agrega una nueva Carta al Cabildo (7), en el tomo $\mathrm{V}$ de su Colección documental (Buenos Aires 1836). Odriozola, sin mencionar su origen, sigue a Angelis en el tomo I de sus Documentos Históricos (Lima 1863).

La Carta al Obispo del Cusco, Juan Manuel de Moscoso y Peralta, escrita el tres de enero de 1781, cuando sitiaba la ciudad, anuncia su acatamienio a la religión, al clero y su defensa de los templos y conventos, recalca su protesta contra los Corregidores y contra los excesivos impuestos, reitera su posición de leal súbdito de Carlos III en contraposición a la deslealtad de las malas autoridades -que burlan las leyes $y$, por ende, la voluntad del monarca-y declara que, satisfecha sus exigencias, se retirará de toda actividad pública. La primera Carta dirigida al Cabildo -que no aparece en la Crónica de Melchor Paz, editada por Eguiguren- también está fechada desde Ocororo el tres de enero de 1781. Aquí señala su prapósito de librar de la exagerada servidumbre a los Indios, amenaza con represalias si, por su guerra "defensiva", los del Cusco cometen venganzas contra sus partidarios, recalca su origen noble, critica los abusos de Corregidores y Curas, se reconoce ejecutor de la sentencia contra el corregidor Arria$\mathrm{ga}$, reclama la inmediato desapárición Cden los Gorregidores y su sustitución por los Alcaldes Mayores, la erección de una Audiencia en el Cuzco y reconoce la autoridad del Rey. La segunda Carta dirigida al Cabildo el nueve de enero de 1781, cuando se preparaba a levantar el sitio de la ciudad, enuncia dos conceptos importantes : primero, recalca que su guerra es defensiva; y segundo, manifiesta que desea la conservación de la ciudad del Cuzco y la escudará del deseo "irreflexivo" de venganza de sus indios que "sólo aspiran a poblarla ellos mismos sin permitir otro vecindario". Aquí hace explícita referencia a la Carta anterior enviada al Cabildo, fechada el tres de enero. Por último, la Carta al Canónigo de La Paz, José Paredes, redactada en Chuquibamba el 26 de enero de 1781, cuando ya se había retirado hacia el

(5) Crónica de Melchor de Paz. Pub. por Luis Antonio Eguiguren. Tomos I-II. I.imn, Imp. Torres Aguirre, 1952.

(6) v. documentos I, III y IV.

(7) v. documento II. 
sur, trae una descripción suya de cómo derrotó al ejército de los Corregidores en Sangarara y da el motivo fundamental de haber levantado el sitio del Cusco, causado por las noticias de marchar tropas enemigas desde el Alto Perú. Alude al avance de las soldados enviados desde Buenos Aires, capitaneados por Flores y por Reseguín, que vencieron a las hermanos Catari y pasaban en auxilio de La Paz, defendida por Segurola y atacada por el nuevo y victorioso jefe indígena Túpac Catari. Además, agrega Túpac Amaru, cómo los españoles no han dejado que el Obispo del Cusco entrase en directas ccnversaciones con él, reitera sus protestas contra las malas autoridades y los excesivos impuestos, hace una crítica de los manejos de la Audiencia de Lima, pone en duda el valor militar de los scldados enviados desde Lima - pues a similares tropas había ya vencido- manifestando con claro humorismo que los limeños "son buenos para matar semitas, y engullir mazamorras". Es particularmente interesante su propuesta al Rey : dar la misma cantidad de dinero que le entregan las autoridades y salvar de esta manera, con su autoridad, la paz y justicia sin detrimento de la Real Hacienda, cosa a la que se siente superlativamente comprometido pcr ser descendiente directo de la dinastía incaica y obligado defensor de los Indios.

El más firme apoyo de les que sostienen el separatismo como nota fundamental delárebelión de Túpac Amaruses un Bando, que se dice haber sido encontrado en uno de los bolsillos del caudillo rebelde - al capturársele en "Langui, a fraición, por quienes en última instancia sólo buscaban el perdón oficial. También lo trae Melchor Paz, lo publica Angelis y lo reedita Odriozola- inserto más adelante (8). Este documento discutible, escrito en Tungasuca, tiene como fecha el 18 de marzo de 1781. Angelis no indica su lugar y fecha. Son muy sospechosos las circunstancias en que manifiestan las autoridades haberlo encontrado. Llama la atención que precisamente cuando Túpac Amaru estaba en plena derrota, redactase tan comprametedor documento y no lo hiciese en el momento en que sitiaba el Cuzco y acababa de vencer a las tropas de los Corregidores. Un detenido análisis de esta pieza muestra, por otra parte, que ni aún en este momento hay un claro separatisma. Túpac Amaru reconocería al Rey y a la Iglesia, aceptaría pagar sendos impuestos, como manifiesta al decir que no se obedezca ni abone suma alguna a las malas autoridades vigentes, "y solo se

(8) v. el Documento V. 
debera todo respeto al Sacerdocio pagandoles el Diezmo y la Primicia como que se da a Dios inmediatamente : y el tributo y Quinto a su-Rey y Señor Natural y esto con la moderación que se hara saber con las demas Leyes que se han de abservar y guardar". La compensación sería reconocerlo de juris como gobernante del Perú, cargo que de facto ostentaba. Este equívoco documento no puede servir de base para una interpretación genérica de separatismo acerca de la rebelión del Cacique de Pampamarca, Tungasuca y Surimana.

En conclusión, puede afirmarse que lo esencial de la rebelión de Túpac Amaru estriba en su carácter de protesta social armada, dentro de una actitud fidelista que acepta la forma monórquica imperante en nuestro siglo XVIII. El separatismo político es una etapa tardía en el Perú, y es anacrónico interpretar los sucesos del siglo XVIII peruano, con las actitudes correspondientes a la vida histórica vigente en el primer cuarto del siglo XIX.

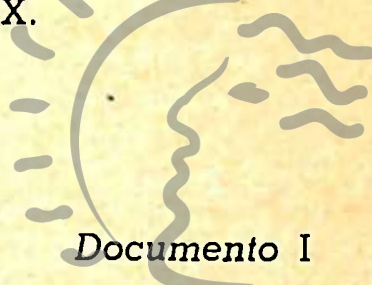

Carta de Túpac Amaru escrita al Sr. Obispo del Cuzco despachada con 3 Emisarios.

Yltm. Señor. El catolico celo de un hijo de la Yglesia, como profeso christiano en el Sacrosanto Bautismo, no puede en ninguna Epoca, ni circunstancias profanar los Sagrados tabernaculos del Dios que adora, ni ofender sus Sacerdotes, a menos de una Causa urgente y licita : siendo para ello mas potisima ( $\mathrm{sic}$ ) la destetación de la fé, y abrazar los extremados torpes vicios del libertinage; $c \mathrm{cn}$ el abuso de las cargas grovosas de unos Fenomenos titulados Corregidores, y las mayores pensiones que se han ido introduciendo con la erección de una general Aduana, y demas gabelas que se inspeccionan a las miserables Puertas de los infelices Vasallos de mi Nacion, propagandola con inexorabilidad un Segundo Pizarro en la tyrania, que no solamente grava a mi Nacion de extraccion, sina aun a las demas naciones y calidades. $Y$ asi esperando que otro, u otros sacudiesen el Yugo de este Faraón, no haviendo salido alguno a la voz, y defenza de todo el Reyno, para escusar los maycres inconvenientes de hurtos, homicidios, ultrages, y otras acciones inucitadas : que aunque hoy se me note de Rebelde, 0 infiel 
a nuestro Monarca Carlos (que Dios guarde) dara a conocer el tiempo que soy un vasallo fiel y leal, y que no he desmentido un punto del debido acatamiento a la Yglesia, y su Magestad.

VSY no se incomode con esta novedad, ni se perturbe con su christiano fervor la Paz de sus Monasterios, cuyas Sagradas Virgenes e inmunidades no se profanaran de ningun modo : ni tampoco sus Sacerdotes seran imbadidos con la menor ofensa, ni injuriados en nada y mas si siguen los designios de mi saneada intencion; que en consiguiendo yo la libertad absoluta de todo genero de pensiones cargadas a mi Nacion, el perdon general de mi aparentada decersion al Vasaliage que debo, y el total demolimiento de la dha. Casa de la Aduana, que intento, y extincion de los rescrtes de Visita, me retiraré a una Tebayda donde picia con sosiego misericordia : y V. S. Y. me imparta todos los senderos y documentos, para mi glorioso fin, que mediante la Divina misericordia, espero, a cuyo servicio aspiro, y a quien clamandole con las mayores ansias ahinces del alma, y rogandole por la importante vida de V.S. Y. su muy seguro servidor. Josef Gabriel Tupac Amaru Inca. Yltm ${ }^{\circ}$ Sr. Dr. Dn. Juan Manuel de Moscoso Y Peralta (9).

\section{Documento II Biblioteca de Letras otro Oticio ali Cabildo del Guzco.}

Muy ilustre Cabildo: Desde que dí principio á libertar de la esclavitud en que se hallaban los naturales de este reino, causada por los correjidores y otras personas, que apartadas de todo acto de caridad, protejian estas estorsiones contra la ley de Dios, ha sido mi ánimo precaver muertes y hostilidades por lo que á mi corresponde. Pero como parte de esa ciudad se ejecutan tantos horrores, ahorcando sin confension á varios individuos de mi parte, y arrastrando otros, me ha causado tal dolor, que me veo en la precision de requerir á ese Cabildo contenga á ese vecindario en iguales excesos, franqueándome la entrada á esa ciudad : porque si al punto no se cumple esto, no podré

(9) Paz : T. I., pp. 285-286. Con ligeras variantes en Angclis : t. V., pp. I8-19, y en Odriozola : Documentos Históricos, t. I., pp. 125-26. Paz y Odriozola ponen como lugar y fecha : Ocororo, 3 de enero de $178 \mathrm{I}$, mientras Angelis pone : Tungasuca, diciembre 12 de 1780 . Angelis está errado en la fecha y el lugar, si nos atenemos al desarrollo cronológico de la rebelión. (v. nota II). 
tolerar un instante de tiempo mi entrada en ella á fuego y sangre, sin reserva de persona. A este fin, pasan el R. P. Lector Fr. Domingo Castro, el Dr. D. Ildefonso Bejarano y el Capitán D. Bernardo de la Madrid, en calidad de emisarios, para que con ellos se me dé fija noticia de lo que ese Ilustre Cabildc resolviese en un asunto de tanta importancia : el que exije rindan todas las armas, sean las personas de cualquiera fuero, pues en defecto pasarán por todo el rigor de una justa guerra defensiva. Sin retener por ningún pretesto á dichos emisarios, porque representan mi propia persona; sin que se entienda sea mi ánimo causar la menor estorsion á los rendidos, sean de la clase que fuesen, como ha sucedido hasta aqui. Pero si, obstinados, intentan seguir los injustos hechos, esperimentarán todos aquellos rigores que pide la divina justicia, pues hasta aqui la he visto pisada por muchas personas.

La mía es la única que ha quedado de la sangre real de los Incas, reyes de este reino. Esto me ha estimulado a procurar por todos los medios posibles, á que cesen en él todo las abusivas introducciones que por los mismos correjidores $y$ otros sujetos se habian plantificado; colocándose en todos los cargos y ministerios unas personas ineptas para ellos, todo resultante contra los mismos indios y demas personas y disposiciones de los mismo reyes de España, cuyas leyes tengo por experiencia se hallan suprimidas y despreciadas, y que desde la conquista acá, no ham mirado aquellos vasallos á adelantarlas, sino que su aplicación es á estafar á esta misma gente, sin que respiren á la queja. Esto es tán notorio, que no necesita más comprobante sino las lágrimas de estos infelices que há tres siglos las vierten sus ojos. Este estado nunca les ha permitido contraerse á conocer el verdadero Dios, sino á ccntribuir á los correjidores y curas su sudor y trabajo : de manera que, habiendo yo pesquizado por mi propia persona en la mayor parte del reino el gobierno espiritual y civil de estos vasallos, encuentro que todo el número que se compone de la gente racional, no tiene luz evangélica, porque les faltan operarios que se la ministren, proviniendo esto del mal ejemplo que se les dá.

El ejemplar ejecutado en el corregidor de la provincia de Tinta, lo motivó el decirme que yo iba contra la iglesia, y para contener los demas corregidores, fué indispensable aquella justicia. Mi deseo es, que este género de jefes se suprima enteramente : que cesen sus repartimientos : que en cada provincia haya un alcalde mayor de la misma nacion indiana, y otras personas de buena conciencia, sin mas inteligencia que la administración de justicia, política cristiana de los indics y demas individuos, señalándoseles un sueldo moderado, con 
otras condiciones que á su tiempo deben establecérseles entre las quo es indispensable una comprensiva á que en esa ciudad se erija Real Audiencia, donde residirá un Virey como presidente, para que los indios tengan mas cercanos los recursos. Esta es toda la idea por ahora de mi empresa, dejándole al Rey de España el dominio directo que en ellos ha tenido, sin que se les substraiga la obediencia que le es debida, y tampoco el comercio comun como nervio principal para la conservacion de todo reino. Nuestro Señor guarde á V. S. muchos años. Campo de Ocororo, 3 de Enero de 1781.- B. L. M. de V. S. su muy sequro servidor.- José Gabriel Tupac Amaru.- Inca.- Muy Ilustre Cabildo y Ayuntamiento de la gran ciudad del Cuzco (10).

\section{Documento III}

Cartas escritas al Cabildo Secular del Cuzco por el Rebelde Tupac Amaru.

Esta Carta fue recibida por mano de los 3 Emisarios a las cinco de la tarde del dia de su fecha (11).

\section{Bibliotecorra. Letras \\ "Jorge Puccinelli Converso"}

Muy llte. Cabildo. Sin embargo de que con fecha cle 3 del que corre expuse $a$ V.S. S. mi deseo propenso siempre a evitar las muertes, destrczos, e incendios de Casas, que no se pueden evitar, si la Guerra defensiva sigue por mi parte. Ayer 8 del mismo haviendose adelantado esta tropa con el ardor que acostumbra, fueron ganando terreno sin hacer ofensa, hasta que la tropa de esa Ciudad declaró la imbacion ofensiva. Las funestas consequencias que se preciso se sigan, me obligan a representar a V. S. S. me veo precisado, a ponerle a la vista me instan mis Yndios a que les conceda permiso para entrar en esa Ciudad a saco. Si asi sucede, quedara arruinada y convertida en cenizas, y sus Habitantes en pabeza, que es la intencion que les he pene-

(1о) Angelis : t. V., pp. $20-21$; Odriozola : Docs. Hist., t. I, pp. 126-28. Jin laz, (pub. L. A. Eguiguren) no se inserta.

(ir) No se inserta la carta enviada al Cabildo e! 3 de enero de $178 \mathrm{r}$. v. Doc. II, que es la Carta mencionada. 
trado, pues me ofrecen entregarla a mi disposicion, y que por compensativo solo aspiran a poblarla ellos mismos sin permitir otro vecindario.

Persuadiranse V. S. S. que esta expresion la dicta el temor, pero no es asi, porque tengo a mis ordenes innumerable gente que solo esperan la que les diese para cumplir lo que prometen. Prevéngolo asi a V. S. S. para que esten en inteligencia de que mi animo deliberado es que no se cause hostilidad a ninguno, y que esos Naturales y Vecindario estan impuestos en lo contrario por persona que debian informarlos de la verdad, mayormente cuando nunca me ha acomodado a las resoluciones atentadas de esta gente, la que anhela a la consumacion de su idea; y recelo pasen a su execusion por aquellos terminos que suele dictar la irreflexion. Para que ante Dios, ni el Rey se me pueda inferir cargo, lo pongo en noticia de V. S. S. para que por medio del conductor Dn. Franciscc. Bernales me comuniquen su deliberacion para ajustar las mias a lo que sea mas conveniente.

Bien penetrado tengo se havran hecho criticas reflexiones sobre adelantar el Real Patrimonio, cesando los Repartimientos por el señalamiento y Alcabala de su tarifa; peró tambien estoy impuesto en que los Mestizos y Españoles gustosos contribuiran a correspondencia de sus fondos aun mas cantidad que el redito de la tarifa. Es bastante prueba de esta verdad hallarse a mis ordenes, sin violencia, crecido numero de ellas, como lo tengo representado a los Tribunales que corresponde. Nuestro Señor guarde a V SS. muchos años. Altos de Piccho y Enero 9 de 1781. B. L. M. de V. SS. su seguro servidor. Josef Gabriel Tupac Amaru Ynca. A los Señores del Ylte. Cabildo y Ayuntamiento de la gran Ciudad del Cuzco (12).

\section{Documento IV.}

Carta que Josef Gabriel Tupac Amaru escribio al Dr. Don Josef Paredes Canonigo de la Iglesia de La Paz Con el motivo de haber este escrito al Dr. Josef Perez en la del Cuzco, solicitando saber de la salud de un deudo suyo que estudiaba en el Colegio de San Bernardo : Y de las novedades ocurrentes cuya posta intercepto el $\mathrm{Dh}^{\circ}$ Rebelde, y le respondio de la manera siguiente.

(12) Paz : t. I., pp. 286-87 : Con pequeñas diferencias, Angclis : t. V., pp. 21-22, y Odriozola : t. I., pp. r28-29. 
Muy señor mio : Con ocasion de hallarme en estos Lugares de Ayaviri trajeron a mi presencia un Yndio que conducia una de V. dirixida al Dr. Dn. Josef Perez; y porque considerando que mis Guardias y Centinelas no le dexaron pasar con grave detrimento, y cristiano celo tan opuesto al de los Europeos que quitan vidas de inocentes sin recelo del daño de sus almas : y porque la de V. se encamina solo a saber las novedades acaecidas en mis progresos, yo sin embozo se las insinuare con el seguro de mi verdad.

Lo primero, murieron los 600 hombres que vinieron a dar guerra. Es evidente que Dn. Tiburcio Landa. Dn. Josef Antonio Urizaga y Guisasola, Dn. Jasef Escajadillo y Dn. Ramon Arechaga vizarros Capitanes salieron en busca mia con mil y mas hombres de distincion, de tropa bien arreglada, quienes perdieron la vida en espacio de una ora $\alpha$ exepcion de quarenta y tantos hombres que a fuerza de mi sudor e industria los pude librar del furor de mis Yndios. Lc segundo, quiere saber V. de la Expedicion del Cuzco, y que si las ocho Parroquias estan a mi favor; a lo que debo decir, que solo siete estan a mi banda (aunque no las havia menester), porque la Parroquia de San Christoval que juzgaban estaba a mi disposicion (porque quando antes regresaba al Cuzco me aposentaba en ella), los Europeos Hereges que la asolaron matando hombres y mugeres sin mas prababilidad que la mala propension de ellos a perjudicar a los miserables Yndios, que con el favor de Dios estan los malvados en lugar donde pagaron lo que han hecho, .pues tengo al Cuzci sitiado con solo once Provincias de gente armada, mo es poca para la que en el recide : pues la causa de mantenerse hasta cora dicha Ciudad en pie, es porque obro como Christiano, procurando con piedad, haciendo porque no dexen asclada la Ciudad, y en ella los Conventos, Monasterios, Monjas, Mugeres y Criaturas : y tambien porque dexando esto en este estado me partí a buscar a Vms. que me decian venian en mi solicitud par Carta que me mandaron mis Espias y Centinelas que tengo en estos Lugares.

El Sr. Obispo de la Ciudad del Cuzco es cierto que mal informado e inquieto su animo se ha compuesto con sus Colegiales alistandolos para la Guerra; pera todo eso creera V. que no tiene subsistencias, sino mucho miedo de los Ladrones Chapetones que lo han obligado.

Me es preciso hacerle a V. una breve insinuación de mi Empresa, la que solamente se dirige a quitar los abusos, malas costumbres y latrocinios $q^{\prime}$ se han experimentada por los que han gobernado en este Reyno : en principal los Corregidores que reparten sus efectos en precios duplicados, y llevarse cada uno de ellos 50,000 pesos y mas de 
cada Provincia aniquilando de plano a los miserables criollos, sin dexarlos pedir a Dios, ni encomendarsele en la Misa, ni Doctrina Christiana, ni ningun acto de fe, sino toda la vida apurados por la cobran$z a$, sin otro Dios que el Corregidor procurando darle todo gusto; $y$ si en algo faltan, el miedo los hace huir a los Chunchos, dexando a sus Mugeres y familias a vivir con ellos, $y$ hacerse en sus costumbres. Ygualmente la Aduana y Alcabala que perjudicaba a todo el Universo, dexando los haberes aun sin el principal: y ultimamente la Mita de Pctosi tan perjudicial que nunca los Yndios volvian a sus Pueblos.

Con apercibimiento de lo que he referido, que aunque podra insinuarlo a la Junta de Guerra de esa Ciudad para su gobierno, he celebrado saber esten prontos con su tropa arreglada. Lo que encargo es sea bien gruesa, y que asi se una con la de Lima, la de la Casta, aunque discurro que para mis fuerzas era necesario reduplicar las armas a las que podran caber en estos Paises porque conozco con individualidad que Dios quiere la conservacion de mi arreglo, pues qualesquiera que han pretendido ir contra mis armas, se han perdido enteramente, sin poner de mi parte medio alguno para su efecto. Vms. se fian mucho en los de Lima: yo he estado en esa Audiencia y tengo observado que estos son buenos para matar semitas, y engullir mazamorras; que tambienen el Cuzco salió una tropa de ellos a quererla entablar con los mios, mas perdieron las vidas en un momento. Solo si son buenos los de aquella Junta para entretener un Pleyto o Demanda, y mantenerse de la sangre de los pobres, como "a mi me acontecia, que habiendo regresado, para alla, discurriendo alcanzar mi pretencion por haver sido justisima con Ynstrumentos evidentes que declaraban mi Descendencia de los Reyes Yngas de este Reyno de quienes soy heredero legitimo y unico : y aunque en dha. Audiencia lo conocieron $\mathrm{y}$ me tenian por tal nunca quisieron declararme enteramente, por no darme lo que corespondía y se me habia señalado por el Monarca. Todo lo que me ha precisado a reparar lo que es de mi obli. gacion, pues ya que Dios Nuestro Señor me ha dado sin atender $a$ mis graves culpas, quiero hacer algun merito para que con el atento a la obligación que me asiste de mirar, y amparar a los del Reyno aunque perdiera mil vidas si las tuviera, pues es en alivio del bien comun, y en contrario solo del mal gobierno, expeliendo solo a los Corregidores y a todos los Chapetones que quieren ir contra mis sanas ordenes.

Aunque concibo que por ellas concebiran, y ponderaran el furor de mis armas, esté V. cierto que el mas infeliz del mundo no es mi animo hacer daño, lo que ratifica que de $\mathrm{mi}$ orden a ninguno han 
muerto sino al Corregidor de Tinta, a quien para exemplar de muchas que daban contra la Yglesia lo mandé colgar, y porque tenia muchos mas meritos para ello; pero a los demas que han procurado hacerme traicion, que es cierto que a los mas de estos he perdonado, por mandar Dios perdonar al Enemigo, no se ha hecho perjuicio. Tambier havran culpadome la quemazón de la Yglesia de Sangarará, pero aseguro a $\mathrm{V}$. que los Caballeros que vinieron, andubieron como unos barbaros, porque haviendose introducido estos en dha. Yglesia, iniciaron la Guerra de alli, y tiraron un cañonazo del qual mataron seis Yndios en el cementerio de la Yglesia. Yo llevaba animo de que nadie pereciese, por lo que escribi una dirigida a los Criollos que alli estaban, y oyendo esto los Chapetones, quitando la vida a varios, estando el Santisimo Sacramento descubierto, fue causa de que el Cura de esa Doctrina cogio a nuestro Amo, y se salio fuera con éli y quisa Dios que la misma polvora que introduxeron adentro, prendió fuego a la Yglesia, y la consumió.

Para que conczca el modo noticio a V . como viendo el peligro en que se hallaba la Ciudad del Cuzco, mandé a dos Embaxadores con dos Sacerdotes y tres Seglares para que les explicasen a lo que iba, ademas de exhibirlo yo por carta al Cabildo Eclesiastico, y Junta de Guerra, y hasta aora no he tenido respuesta. Y aunque el Sr. Obispo quizo responderme personalmente saliendo $\alpha$ mi Real a hablarme, so io bala desviada, y de estelmodo se ha procurado el bien del alma del impidieron los malbadose atemorizandolonquespodia morir crin alguna europeo de quitarsele que robe, por lo que se pierde toda una Ciudad.

Tengo hecho Ynforme a S. M. representandole mi designio, $y$ prometiendole adelantar otro tanto de lo que daban los ladrones del Reyno; y V. crea que asi se mantendria en paz y quietud, y que repararán en cosas de Dios con la adoracion debida, sin tener muchos Dioses Corregidores ni Ministros que con Capa de Su Magestad,hostilizan mas a los miserables. Todo esto se ha procurado por mi parte, ser mi cbligacion hacerlo por ultimo Descendiente del Rey último del Perú, y su heredero: y no havia quien se dedicase a librarlos de manos de Faraon. Mucho mas dixera a V. en estos asuntos; pero las ocupaciones no me dan lugar, y solo ruego a Nuestro Señcr me lo ge. ms. as. Chuquibamba y Enero 26 de 1781. B.L.M. de V. su seg'

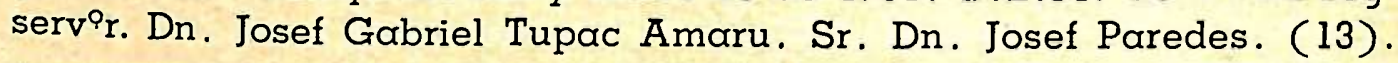

(13) Paz: t. v., pp. 329-332. Angelis la omite, pero se descubre que la utiliza en su Relación histórica inicial. Odriozola - que sigue a Angelis - tambión la ignora, 
Documento $V$.

Edicto que se le halló al Rebelde Tupac Amaru en la faltriquera del Vestido quando fue preso.

Dn. Jasef por la gracia de Dios Ynga Rey del Peru, Santa Fe, Quito, Chile, Buenos Ayres y Continentes de los Mares del Sur, Duque de la Superlativa, Señor de los Cesares y Amazonas con Dominoi en el gran Paititi, Comisario Distribuidor de la Piedad Divina \&.

Por quanto es acordado por mi Consejo en Junta prolija por repetidas ocasiones, ya secreta, y ya publica, que los Reyes de Castilla me han tenido usurpada la Corona y Dominio de mis Gentes cerca de tres siglos, pensionandose los Vasallos, con insoportables Gabelas, tributos, Sisas; Lanzas, Aduanas, Alcabala, Estancos, Catastros, Diezmos, y Quintos, Virreyes, Audiencias, Corregidores y demas Ministros todos iguales en la tyrania, vendiendo la Justicia en Almoneda con los escrivamos de esa fé a quien mas puja y quien mas da, entrando en esto los Empleos Eclesiasticos y Seculares sin temor de Dios, estropeando ccrmo a bestias a los Naturales de este Reyno, quitando las vidas a solo los que no supieren robar; todo digno del mas severo reparo: por eso, y porque los justos clamores con generalidad han llegado al Cielo. En el Nombre de Dios. Todo Poderoso ordenamos y mandamos que a ninguna de las Perschas dichas se pague ni se obedezca en cosa alguna a los Ministros Europeos intrusos, $y$ solo se debera todo respeto al Sacerdocio pagandoles el Diezmo y la Primicia como se da a Dios inmediatamente : y el tributo y Quinto a su Rey y Señor Natural y esto con la moderacion que se hara saber con las demas Leyes que se han de observar y guardar. Y para el mas pronto remedio de todo lo suso expresado, mandamos se reytere y publique la Jura hecha de mi Real Coronacion en todas las Ciudades, Villas, Lugares de mis Dominios dandonos parte con toda brevedad de los Vasallas prontos y fieles para el premio igual : y de los que se rebelaren para la pena que les competa remitiendonos la Jura fecha cen la razon de quanto conduzca. Fecho en Tungasuca a 18 de Marzo de 1781. Don Josef Gabriel Tupac Amaru Ynga Rey del Perú. (14).

(14) El Edicto ha sido publicado con ligeras modificaciones. Paz: t. I, pp. $361.62 ;$ Angelis: t. v. pp. 104-05; Odriozola: Docs. Hist., t. I, pp. 206. Paz y Odrio. zola ponen como fecha y lugar, el 18 de marzo de 1781 en Tungasuca; Angelis no trae mención de lugar ni fecha. 